\title{
HOW COST EFFECTIVE IS THE TREATMENT? ARE PRESCRIBERS CONCERNED?
}

\author{
Das B P*, Naga Rani M A*, Rauniar G P*, Sangraula H*
}

\section{ABSTRACT}

Cost-effective treatment should be of primary concern to prescribers in poor countries like Nepal. The present study was carried out at a tertiary care hospital in Nepal to find out the perception of prices of commonly prescribed drugs among prescribers. The participants selected randomly were directed to write in 10 minutes on a proforma, the generic name(s) and price of the brand preparation of 18 most commonly used drugs listed under their brand name.

The price of the drug was considered correct if the price mentioned was within a range of $20 \%$ above or below the brand price. Results indicated that the participants were aware of the composition of majority $(80 \%)$ of the drugs, but were not aware of the prices of $81.80 \%$ of the drugs. No single participant mentioned the correct prices of all the drugs. Among the drug groups studied, the most accurate data was provided about composition $(\mathbf{9 0 . 4 3 \%})$ and price $(\mathbf{2 4 . 4 7 \% )}$ ) of non steroidal anti-inflammatory drugs (NSAIDs). Only in $9.22 \%$ of brand preparations of antimicrobial agents (AMA), the prices were mentioned correctly. Hence, sensitisation of physicians about cost-effective treatment is of immense importance and to facilitate this, hospital authorities could provide prescribers with regularly updated price lists of commonly prescribed drugs and competitive prices of various brand preparations. Pharmacoeconomics may be introduced in the undergraduate curriculum which can be reinforced by continuing medical education.

Key Words: Cost-effective, Pharmacoeconomics.

\section{INTRODUCTION}

The prescription order is an important transaction between physician and patient. ${ }^{1}$ The prescribing behavior of doctor depends upon various factors like patients, professional colleagues, academic literature, commercial publicity and government regulations. Continuous monitoring of prescriptions may help to identify problems involved in therapeutic decisions and promote rational prescribing. ${ }^{2}$ Though rising trend in drug prices is one of the important causes of poor patient compliance, ${ }^{3}$ cost-effective prescribing is not given much attention. Patient compliance may be increased by choosing the least expensive among equieffective drugs. ${ }^{4}$ However, expensive drugs are often prescribed, due to lack of knowledge of prices of marketed drugs leading to patient non-compliance. ${ }^{5}$ Incomplete treatment due to noncompliance itself can result in long term consequences such as enhanced resistance to antimicrobial agents. Hence, awareness of cost of treatment in local currency in relation to the per capita income is essential for both ethical and

* B.P. Koirala Institute of Health Sciences, Dharan, Nepal.

Address for correspondence : $\quad$ Dr. B. P. Das

Department of Pharmacology

B.P. Koirala Institute of Health Sciences, Dharan, Nepal.

Email: bpdas2000@yahoo.com 
economic reasons. ${ }^{6}$ Since, prices of drugs vary between brand preparations, prescribers' knowledge of competitive prices of various brand preparations also is essential. The present study was carried out to find out the awareness of doctors at BPKIHS, a tertiary care health center in eastern Nepal, about the prices of brand preparations.

\section{METHODOLOGY}

A total of 47 physicians selected randomly were provided with a proforma to write in 10 minutes their professional details and the generic name(s) and price of 18 most commonly used drugs listed with their brand names. The price within a range of $20 \%$ above or below the brand price mentioned in the Drug Index ${ }^{7}$ was considered to be correct. The data was analysed and tabulated.

\section{RESULTS}

The mean age of the participants was 31.88 years (SD-4.89) and consisted of 45 males and 2 females. Among them, $42.55 \%$ of participants had postgraduate (MD/MS) qualification, $14.89 \%$ were graduates (MBBS) and the rest did not mention their educational status. Majority of the participants (40.42\%) had 5-10 years of experience while $31.91 \%$ had less than 5 years of experience. (Table I). Table IIa, b, c \& d respectively

Table IIc : Participants' response regarding brand preparations of hematinics \& vitamins $(n=47)$ 